\title{
Extent and Effect of Horizontal Supply Chain Collaboration among Construction SME
}

\author{
Anders Björnfot ${ }^{1}$ and Liv Torjussen ${ }^{2}$ \\ ${ }^{1}$ Assistant Professor, Division of Construction and Production Engineering - Timber Structures, Lulea University of \\ Technology, Lulea, Sweden, E-mail: anders.bjornfot@ltu.se (corresponding author). \\ ${ }^{2}$ Assistant Professor, Faculty of Technology, Economy and Management, Gjovik University College, Gjovik, Norway, E- \\ mail: livt@hig.no
}

Project and Production Management

Received September 27, 2011; received revision November 3, 2011; accepted November 24, 2011

Available online December 19, 2011

\begin{abstract}
The majority of companies involved in value delivery in the Swedish housing industry are Small- and Medium-sized Enterprises (SME). An SME is often managed in an informal way with focus on sales and production. Many SME are also financially vulnerable as they are strongly dependent on a few key customers and key products. As variation will always exist, SME should learn to deal with variation instead of try eliminating it. This paper hypothesises that structural flexibility in SME supply chains through horizontal collaboration leads to a regional environment of economical growth from which all active SME will benefit. The hypothesis is examined through two case studies; a Swedish supplier network that has worked together six years and a four year old Norwegian supplier network. A benefit of collaboration is knowledge sharing that lessens the economical strain of keeping up with the "latest". Other examples of collaboration are shared production resources in case of low capacity. Collaboration within supplier tier networks is considered to mark the emergence of a "collective strength" that improves individual suppliers bargaining position towards their customers. This evolution is considered an indication of the emergence of a "Lean Enterprise" within the house building sector.
\end{abstract}

Keywords: Supply chain management, horizontal collaboration, value delivery, construction suppliers, small and medium sized enterprises (SME).

\section{Introduction}

As an enterprise's economy grows its collaborative efforts are likely to change from regional interests, to industry and later sector interests as collaboration stem from selfinterests (Simatupang and Sridharan, 2002). This can be exemplified from the construction sector where large contractors generally collaborate across supply chains (Fig. 1) in strategic questions that involve the construction sector at large, i.e. political questions such as new construction regulations, raised transportation taxes, etc. These questions are critical for the growth of the construction sector at large, and hence, required for economic growth of individual enterprises.

Industrialised house-builders (Stehn and Höök, 2008) represents a relatively young niche in the housing industry where enterprises instead collaborate (Fig. 1) to increase the market share of industrialised housing by joint development of, for example, new innovative building systems (Björnfot and Stehn, 2007) and improved service systems (Lennartsson and Björnfot, 2010). Collaboration among SME (Fig. 1) is of course also governed by selfinterests; survivability on volatile markets.

The plights of small- to medium-sized enterprises (SME) are many. Many SME are financially vulnerable as they are strongly dependent on a few key customers and key products (Radas and Božić, 2009). An SME is often managed in an informal way, often with an excessive focus on sales and production (Nilsson, 2010). SME with growth ambitions often end up in financial problems (Cressy and Olofsson, 1997) and they often have problems recruiting required competences (Nilsson, 2010). Also, development of organizational and economic management systems rarely accompanies growth in sales (Greenhalgh, 2000). Sacks (2004) identify similar plights for construction subcontractors as they struggle to share their resources among multiple simultaneous projects for improved profitability.

SME are generally too small for their voices to be heard at the construction sector or housing industry levels (Fig. 1). Therefore, construction SME should opt for alternative routes for increased profitability and survivability on volatile markets as winning the customs and loyalties of end users becomes more difficult as the competitive environment becomes more volatile (Power, 2005). Christopher and Holweg (2011) argued that enterprises should become more adaptable to their environments by building in structural flexibility into their supply chains. As variation will always exist in one form 
or another, structural flexibility accepts variation and deals with it instead of struggling to eliminate it.

According to Sandberg (2007), internal excellence is not enough anymore; there is also a need for external excellence in the whole supply chain. This paper hypothesises that structural flexibility in SME supply chains through horizontal collaboration (Prakash and Deshmukh, 2010) will lead to a regional environment of economical growth from which all active SME will benefit, i.e. the missing strategic dimension in supply chain management as argued by Sandberg (2007). This environment is what in this paper is referred to as a Lean Enterprise (Womack and Jones, 1994), a horizontal collaboration where SME will thrive. Benefits and opportunities of horizontal supply chain collaboration among SME in the housing industry are examined through two case studies; a Swedish supplier network that has worked together for six year and a four year old Norwegian supplier network.

\section{Theory - Horizontal Supply Chain Collaboration}

In the current competitive industrial context, enterprises must react quickly to market changes. In order to face this problem, enterprises must collaborate. According to Cao et al. (2010), supply chain collaboration is two or more autonomous firms that form long-term relationships and work closely to plan and execute supply chain operations. The goal of collaboration is to improve overall performance for the benefit of all chain members (Prakash and Deshmukh, 2010). A collaborative supply chain is, according to Simatupang and Sridharan (2002), commonly differentiated in terms of its structure in vertical, horizontal and lateral (Fig. 2), where supply chain collaboration most commonly is realised horizontally or vertically in a supply chain (Carpinetti et al., 2007).

Horizontal supply chain collaboration is not as frequently approached in literature as its vertical counterpart. Simatupang and Sridharan (2002) stated that horizontal supply chain collaboration occurs when two or more unrelated or competing organizations cooperate to share their private information or resources such as joint distribution centers, and shared manufacturing capacities (Barratt, 2004). Horizontal supply chain management thus means to cooperate across, rather than along, supply chains composed of both competing and non-competing companies (Fig. 2).

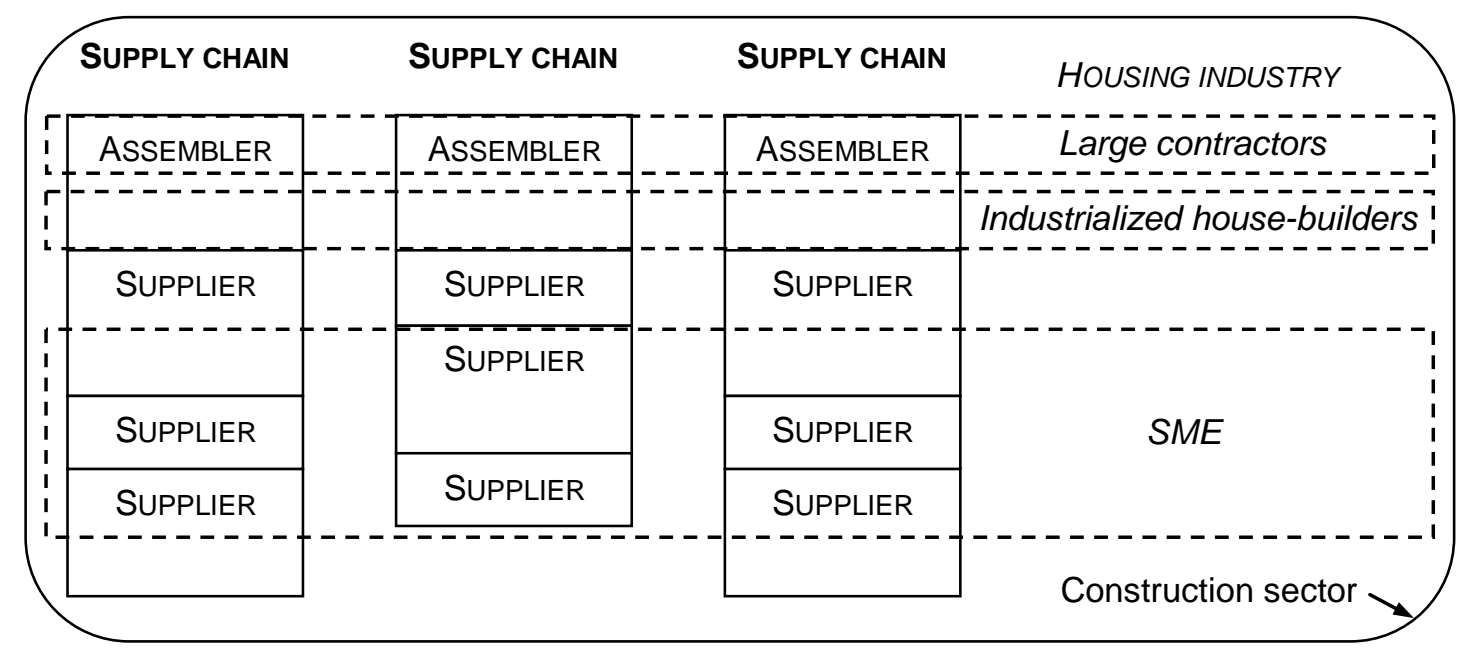

Fig. 1. Illustration of collaboration efforts in the housing industry.

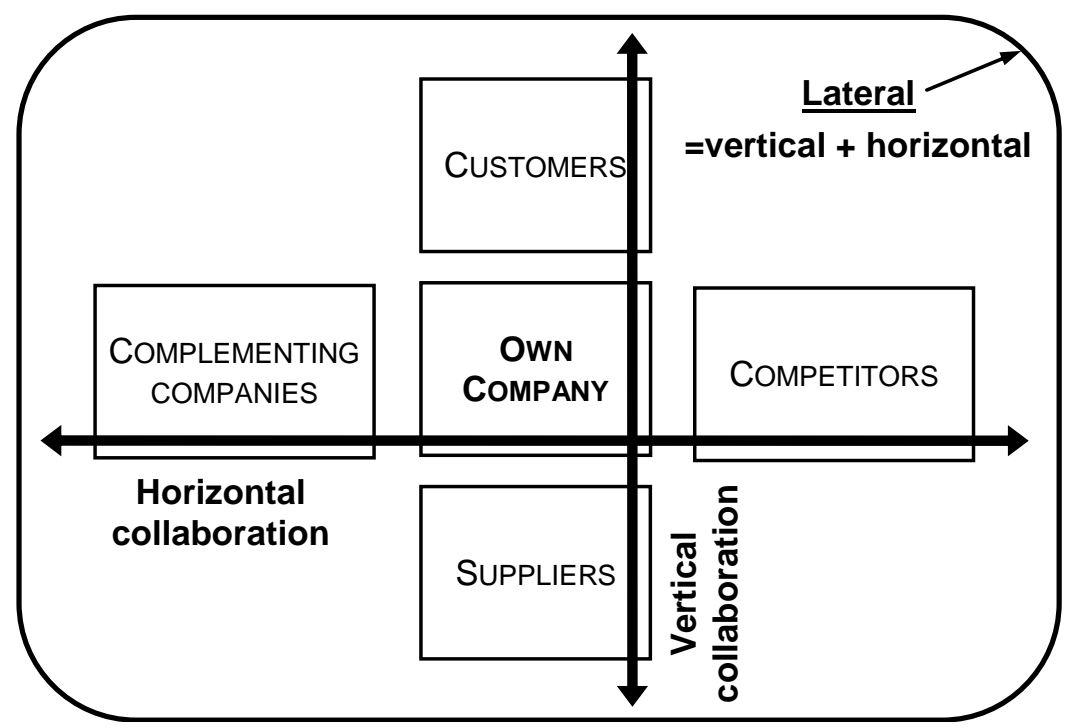

Fig. 2. Illustration and definition of vertical and horizontal supply chain collaboration (inspired from Barratt, 2004). 
Horizontal collaboration can, according to Prakash and Deshmukh (2010), reduce the overall cost of the supply chains and the enterprises can improve the real time decision making process by adopting a suitable inventory policy. Other objectives and possible outcomes of horizontal supply chain collaboration are (Simatupang and Sridharan, 2002; Barratt, 2004; Mason et al., 2007; Prakash and Deshmukh, 2010):

- Reduced logistics cost results in improved use of transport/storage facilities and economies of scale in deliveries to customers.

- Higher service levels leads to shorter throughput times to customers as well as more frequent deliveries to customers.

- Higher turnover/market share provides collaborative distribution channels to customers and shared offers for new/potential customers.

- Reduced investments leads to shared investments in distribution centres and handling as well as shared investments in transports.

- Sustainable logistics results in reduced $\mathrm{CO} 2$ footprint and improved use of fuel and energy.

- Knowledge exchange provides an exchange of best practices and the sharing of innovation.

\subsection{Evaluating Horizontal Supply Chain Collaboration}

Sandberg (2007) stated that the literature on supply chain management becomes fuzzy about what actually occurs when companies collaborate and what specific effects are achieved. In current supply chain practices, enterprises seek to create dynamic flexibility, which allows firms to cope with shifts in demand and technology within their existing supply chains. However, Christopher and Holweg (2011) argue that turbulence such as increasingly demanding customers and increasing uncertainty in global markets are features of times to come. Therefore, Supply chains need to adopt structural flexibility that builds flexible options into the design of supply chains.

A volatile environment is characterised by industry structural instability, information unverifiability, and law unenforceability (Lou, 2007). Increased control efforts in supply chains in volatile environments results in rigidity which may result in amplification of variability rather than dampening. According to Christopher and Holweg (2011), this is because the supply chains have been designed with efficiency rather than flexibility in mind. Supply chains that achieve structural flexibility do so through a number of actions (Christopher and Holweg, 2011):

- Dual sourcing, by having alternative sources for key raw materials and major components.

- Asset sharing, i.e. being prepared to share physical assets such as factories, distribution centres or trucks with other companies.

- Separating demand, by recognizing that most products will have a base level of predictable demand that can be planned for. Demand over the base level ("surge") can be managed through the use of postponement techniques.

- Postponement, by holding the base materials, subassemblies, and modules as strategic inventory and assembling or configuring the products against actual orders.

- Flexible labour, by utilizing "annual hours" agreements or by making use of agency personnel, so that the labour force can be adjusted - with little or no cost penalty - to meet seasonal demand swings through the years, as well as shift is demand over the product life cycle.

- Rapid manufacture, by using new technology to enable the economic manufacture of products in small batches in relatively small facilities, thus permitting dispersed manufacturing.

- Outsourcing, to external providers, such as contract manufacturers and third-party logistics firms, to gain access to capacity when required and convert fixed costs into variable costs.

Expected outcomes of horizontal supply chain collaboration can be evaluated through the actions for structural flexibility. Reduced logistic costs can, for example, be obtained by applying a postponement strategy or sharing assets, and reduced investments can be obtained by, for example, outsourcing strategies. In order for SME in the housing industry to become more competitive on volatile markets they should adopt actions for structural flexibility (Fig. 3) through collaboration with both competitors and complementing companies (Fig. 2) in order to improve its structural flexibility and market stability. Case studies of Swedish and Norwegian SME networks are used to examine the extent and effects, of horizontal collaboration.

\begin{tabular}{|c|c|c|c|c|c|c|}
\hline $\begin{array}{c}\text { Dual } \\
\text { sourcing }\end{array}$ & $\begin{array}{c}\text { Asset } \\
\text { sharing }\end{array}$ & $\begin{array}{c}\text { Separating } \\
\text { demand }\end{array}$ & $\begin{array}{c}\text { Postpon } \\
\text { ement }\end{array}$ & $\begin{array}{c}\text { Flexible } \\
\text { labour }\end{array}$ & $\begin{array}{c}\text { Rapid } \\
\text { manufacture }\end{array}$ & $\begin{array}{c}\text { Outsourc } \\
\text { ing }\end{array}$ \\
& & & & & &
\end{tabular}

Fig. 3. Characterization of a fully structural flexible supply chain. 


\section{Method - Evaluating Horizontal Supply Chain Collaboration}

\subsection{Categorization of Individual SME and their Extent of Collaboration}

To evaluate collaboration it must be clarified whether the involved SME compete or complement each other (Fig. 2) and whether there is a state of power dictating the collaboration, i.e. if an SME has more "economic muscles" compared to its partners. The extent of collaboration is analysed by judging the SME product offer (Fig. 4), i.e. the individual enterprises position in the value chain (Björnfot and Stehn, 2005; Björnfot and Stehn, 2007). The power relation between individual SME is analysed through a combined evaluation of their annual turnover and employees (Fig. 4).

\subsection{The Swedish SME Network}

The network has been active for at least six years in northern Sweden. The network contains about sixty SME where about twenty of these are active in network activities on approximately weekly basis. The SME are saw milling enterprises, furniture and interior manufacturers, construction component manufacturers (door, windows, etc.), construction element manufacturers (wall and floor elements) and detached housing manufacturers, i.e. they encompass the whole value chain as illustrated in Fig. 4.

A privately owned organization dedicated to SME development supports development activities. In the network there is close cooperation with universities and other research institutes as well as other organizations focused on, for example, export. The network is externally funded from the government, involved municipalities and the European Union. Common network activities include participation at fairs and exhibitions, arrangement of workshops and seminars, aid (monetary and competence) in product and production development, etc.

\subsection{The Norwegian SME Network}

The Norwegian network is active in south-eastern Norway. The network has been active for about four years and involves approximately 15 enterprises ranging from saw mills to construction component manufacturers (trusses, wall elements, roof element, etc.), detached housing producers and producers of housing in multiple floors, i.e. basically the whole value chain is involved (Fig. 4), similar to the Swedish network. Most of the enterprises involved in the Norwegian network are of small to medium size, compared with mostly micro to small sizes in the Swedish network according to Table 1.

The network involves collaboration with academia and other research and development organizations. Network activities include activities aimed at improving cooperation as well as individual SME competitiveness. Other focused activities are to increase industrialisation by, for example, joint study visits to other SME (a study visit was performed to the Swedish network) and the development of a new education at the local university collage, specifically catered to the needs of the regional SME.

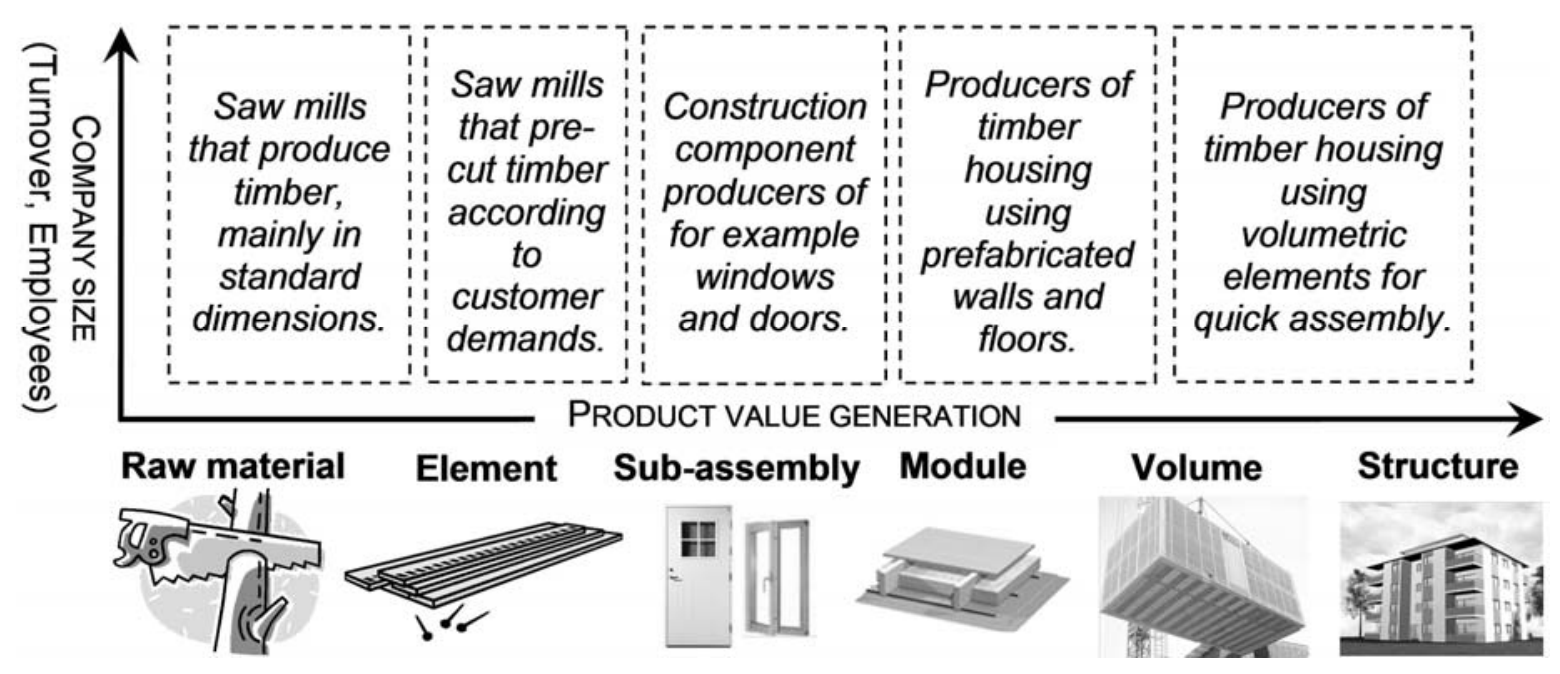

Fig. 4. Characterization and exemplification of SME product offer.

Table 1. The European Commission's characterisation of SME

\begin{tabular}{|c|c|c|c|c|}
\hline Enterprise category & Headcount & Turnover & or & Balance sheet total \\
\hline Medium-sized & $<250$ & $\leq € 50$ million & & $\leq € 43$ million \\
\hline Small & $<50$ & $\leq € 10$ million & & $\leq € 10$ million \\
\hline Micro & $<10$ & $\leq € 2$ million & & $\leq € 2$ million \\
\hline
\end{tabular}




\subsection{Data Collection}

The Swedish and Norwegian networks of SME construction suppliers (in actuality most involved suppliers are of small size and even micro enterprises Table 1) were studied over a three year period through active participation by the authors who worked as "academic project leaders" (university representatives in a company driven collaboration effort). Active participation included involvement at multiple project meetings, seminars, workshops, study visits, continuous communication with project leaders (consultants) responsible for direct development of companies, as well as individual communication with SME both involved in network activities and SME who, for a multitude of reasons, decided to remain outside the networks.

A total of three characteristic examples of horizontal collaboration were decided on to be studied in-depth. The examples are considered to characterise the collaborative environment in both studied networks. The examples was decided on based on two criteria; 1) Willingness to take part in external R\&D efforts and 2) Extent of collaboration efforts. The rationales for each of the three examples are:

\section{- Collaboration Example 1:}

Involves two highly $\mathrm{R} \& \mathrm{D}$ active SME in the region.

\section{- Collaboration Example 2:}

Involves seven active SME who have collaborated in many different activities, e.g. production and sales, over a long time-period.

\section{- Collaboration Example 3:}

Involves three SME who has teamed up with a much larger saw-mill for an extensive and costly product development endeavor.

\section{Results \& Analysis - Extent of Structural Flexibility in SME Collaboration}

\subsection{Collaboration Example 1 - Coordinated Production of Interior Solutions}

SME 1 (Fig. 5) mainly produce interior solutions and furniture. They supply furnishing and storage furniture, desks and other special carpentry to libraries, hotels, offices and other projects that have special requirements, but where size of the order requires cost-effective production and management. Consequently, their core products are mainly low volume orders, mostly lacking the organisation and production efficiency to be competitive on large volume bulk orders.

SME 2 (Fig. 5) manufactures and delivers complete interiors for public spaces. They produce everything from reception desks to complete interior solutions for restaurant and hotel rooms. In recent years they have invested in modern machinery and specialize in furnishings for public spaces. They compete on the same market as SME 2 with similar products. SME 1 and SME 2 are located a mere $100 \mathrm{~km}$ 's apart.

Collaboration between the two competing SME has been ongoing for about seven years. Examples of collaboration efforts (characterized in Fig. 6) include:

- Both SME made individual bids for the interiors of a hospital reception. SME 1 won the tender. At the same time SME 1 also won a tender on the delivery of interiors for a library. For this project they lacked production resources. To fulfil both contracts, SME 1 allowed SME 2 to produce the library interiors. This is but one example of outsourcing between the two SME where they use each other as extra capacity in time of need.

- During the delivery of interiors to a large local cultural building, of which both SME 1 and SME 2 had contracts, albeit for different parts, purchasing of materials was coordinated in order to reduce the costs. This is but one example of asset sharing, where collaboration results in improved bargaining power.

- SME 2 has invested in modern CNC machinery. SME 1 frequently ask SME 2 to produce their complex parts, e.g. drilling of dense holes in large massive timber plates requires special machinery for cost-effective, rapid manufacturing.

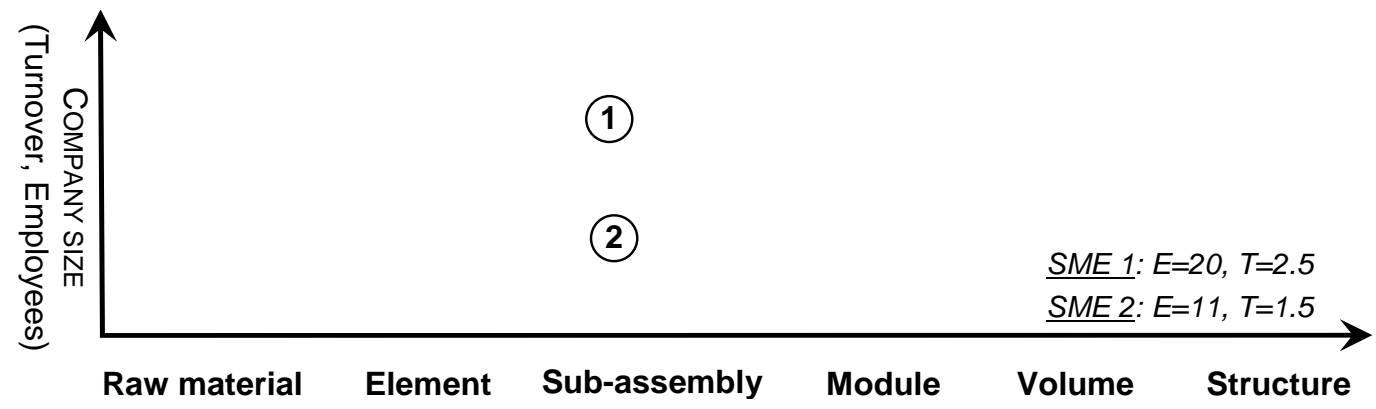

Fig. 5. Characterization of SME in collaboration example $1(\mathrm{E}=$ number of employees and $\mathrm{T}=$ Annual turnover in $\mathrm{M} €)$.

\begin{tabular}{|c|c|c|c|c|c|c|}
\hline $\begin{array}{c}\text { Dual } \\
\text { sourcing }\end{array}$ & $\begin{array}{c}\text { Asset } \\
\text { sharing }\end{array}$ & $\begin{array}{c}\text { Separating } \\
\text { demand }\end{array}$ & $\begin{array}{c}\text { Postpon } \\
\text { ement }\end{array}$ & $\begin{array}{c}\text { Flexible } \\
\text { labour }\end{array}$ & $\begin{array}{c}\text { Rapid } \\
\text { manufacture }\end{array}$ & $\begin{array}{c}\text { Outsourc } \\
\text { ing }\end{array}$ \\
\hline
\end{tabular}

Fig. 6. Characterization of efforts for structural flexibility in example 1. 


\subsection{Collaboration Example 2 - Coordinated Furniture Sales}

The furniture network, composed of six furniture manufacturers (Fig. 7), was created to improve the sales of the involved SME. The network includes SME 1 and SME 2 from example 1. SME 3-6 are smaller enterprises with fewer than eight employees, where one enterprise is a oneperson business, a carpenter who produces furniture's by hand in a traditional manner. The network product range is furniture's for dining rooms, bed rooms, as well as individual cupboards and bookshelves. All companies are small and, therefore, they cannot compete with larger manufacturers on price alone. To aid in marketing and sales of their products, a sales enterprise (SME 7) was contracted and eventually included as a partner in the network.

Collaboration between the involved companies is active in many areas. Examples of collaboration efforts (characterized in Fig. 8) include:

- All orders are received by SME 7 who distribute production to the different manufacturers based on quality, costs and availability of production capacity. This is a good example of successful dual sourcing where different SME can produce individual components when asked to. In this case, SME 7 has also effectively outsourced its production to SME 1-6.

- Development of a common Enterprise Resource Planning (ERP) system for efficient coordination of sales, production and logistics. The ambition is to make sure that SME 1-6 all receive work and become profitable. This is an example of asset sharing where all production resources available in the network are at the beck and call of SME 7 who distribute the orders.

- The network has jointly established a distribution centre (DC) to coordinate deliveries to furniture traders (mostly to long-distance traders located in southern Sweden) allowing more optimal finished goods batches that can be managed based on inventory level, i.e. as customers pulls finished goods from the DC, a signal is sent back to the producers. The DC enables a postponement strategy where a finished goods inventory is held based on customer demands, that together with separating demand, allows the assembly of finished goods that is composed of components from many different producers.

\subsection{Collaboration Example 3 - Coordinated Product Development}

Three SME has joined together with a large saw milling enterprise to develop and produce a new kind of heattreated wood for new construction applications, for example durable façades, interior claddings, heat transfer resistant products, etc. Characterization of involved SME in collaboration example 3 is shown in Fig. 9.

SME 1 calls themselves one of Sweden's most innovative producers of wood products that are primarily intended for outdoor use. Their capabilities include round lathed and pressure-treated wood products, designed according to customer demands.

The product range of SME 2 consists of interior and exterior panels, laths and other timber products, as well as a large assortment of rails and pressure treated wood products. They also perform priming and painting of exterior panels.

SME 3 is a family owned smaller saw milling company that grades timber in 26 different standards for maximum customer choice. They also offer planning of timber. It is not unusual that SME 1 and SME 2 purchase their timber from SME 3.

The involved SME are not direct competitors, instead their individual products complement each others on many occasions. The goal of the product development is to find new applications for their individual products. However, there certainly are other collaboration efforts (characterized in Fig. 10) between the SME:

- Extensive R\&D of the new material and the design of an optimal production process. This is an example of asset sharing as the development is made in conjunction, i.e. they are all effectively sharing the risk.

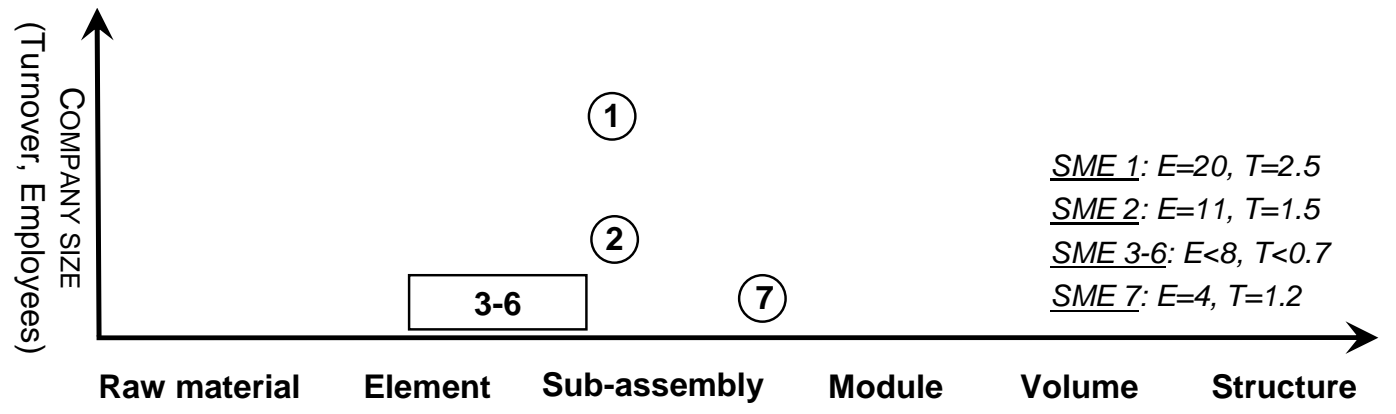

Fig. 7. Characterization of SME in collaboration example $2(\mathrm{E}=$ number of employees and $\mathrm{T}=$ Annual turnover in $\mathrm{M} €)$.

\begin{tabular}{|c|c|c|c|c|c|c|}
\hline $\begin{array}{c}\text { Dual } \\
\text { sourcing }\end{array}$ & $\begin{array}{c}\text { Asset } \\
\text { sharing }\end{array}$ & $\begin{array}{c}\text { Separating } \\
\text { demand }\end{array}$ & $\begin{array}{c}\text { Postpon } \\
\text { ement }\end{array}$ & $\begin{array}{c}\text { Flexible } \\
\text { labour }\end{array}$ & $\begin{array}{c}\text { Rapid } \\
\text { manufacture }\end{array}$ & $\begin{array}{c}\text { Outsourc } \\
\text { ing }\end{array}$ \\
\hline
\end{tabular}

Fig. 8. Characterization of efforts for structural flexibility in example 2. 


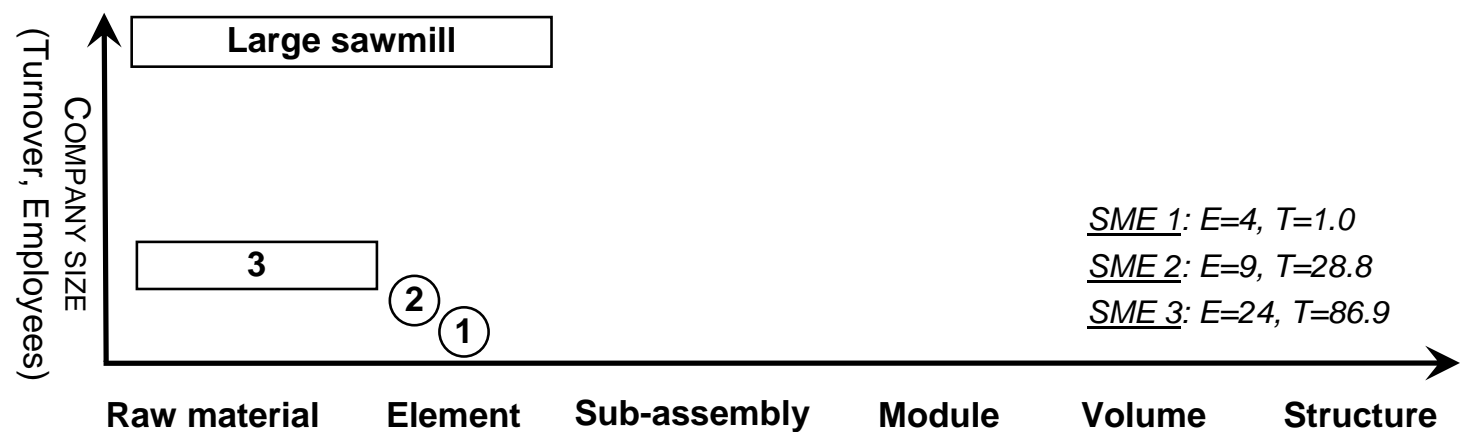

Fig. 9. Characterization of SME in collaboration example $3(\mathrm{E}=$ number of employees and $\mathrm{T}=$ Annual turnover in $\mathrm{M} €)$.

\begin{tabular}{|c|c|c|c|c|c|c|}
\hline $\begin{array}{c}\text { Dual } \\
\text { sourcing }\end{array}$ & $\begin{array}{c}\text { Asset } \\
\text { sharing }\end{array}$ & $\begin{array}{c}\text { Separating } \\
\text { demand }\end{array}$ & $\begin{array}{c}\text { Postpon } \\
\text { ement }\end{array}$ & $\begin{array}{c}\text { Flexible } \\
\text { labour }\end{array}$ & $\begin{array}{c}\text { Rapid } \\
\text { manufacture }\end{array}$ & $\begin{array}{c}\text { Outsourc } \\
\text { ing }\end{array}$ \\
\hline
\end{tabular}

Fig. 10. Characterization of efforts for structural flexibility in example 3.

- The development and construction of a new plant for production of the new heat-treated wood. This is another example of asset sharing as the new production plant is to be shared by all involved SME.

- Joint development of innovative application of the new material, for example a new window was developed to severely reduce heat conduction. This is an example of dual sourcing; the knowledge is considered a core competence.

\subsection{Examples of other Collaboration Efforts}

There are plenty of other ongoing collaboration efforts within the Swedish and Norwegian networks. Some good examples of these are:

- Seven detached housing SME have joined together with Sweden's largest detached housing producer and a large multi-storey timber housing producer in a combined effort to better market the regional housing industry. Joint activities are, for example, workshops with local municipalities and landlords.

- In northern Sweden there has been a long-time on-going effort to coordinate competences and education in the timber industry. Activities performed have included companies from all parts of the value chain and the work has led to development of an internet based competence platform for coordination of SME competence requirements.

- Participation at fairs is a key activity leading to increased business for individual SME but additional cross-wise orders are not uncommon, i.e. where competitors also receive orders. Therefore, competing SME share stands with the argument that 'two are seen more easily than one'.
- There exists a similar network to the one presented in example 2 above composed of two competing SME and three design SME that jointly market their products through a common web-page as well as coordinate sales.

- In both the Swedish and Norwegian networks, competing SME sit together at the same table and openly discuss how to improve the regional industry, arguing that "my own competitiveness and business will improve if the business climate surrounding my enterprise grows".

\section{Discussion - Extent and Effect of Horizontal Supply Chain Collaboration}

In the provided examples, collaboration mainly occurs through dual sourcing, asset sharing, and outsourcing. Consequently, there are in all examples opportunities to further improve horizontal collaboration through, for example, separating demand, postponement strategies, as well as application of flexible labour and rapid manufacturing. It seems that structural flexibility results in shared resources and capabilities among the collaborating SME. Application of joint resources thus seems a way to enable structural flexibility among collaborating SME:

- Marketing and sales is crucial for any company but maybe more so for SME who have limited product portfolios. Pooling together products from different SME that are marketed and sold jointly can potentially lead to additional businesses that will further promote their individual products.

- Research \& development is a major hindrance for SME that wants to grow as they rarely have an economic margin to use to develop their current businesses. However, it is imperative that the SME are inclined to grow as standing still could mean being outpaced by competitors, leading to economic decline. 
- Logistics through the development of additional distribution centres that should be linked to postponements strategies to further increase the structural flexibility. This implies the need of additional assemblers; either through new formed enterprises specialized in assembly or through current SME that decided to integrate their businesses further downstream in the value chain.

- Supply of competences should occur through a joint development of a competence platform that acts as a hub that brings together suppliers of competences and education as well as companies seeking the same. As a matter of fact, such an initiative is under development in the Swedish network (however, the funding for this endeavour is mainly from the government).

Horizontal supply chain collaboration can be linked to other Lean initiatives. For example, agility as used in Lean (Lu et al., 2011) means that market knowledge and virtual corporations are used to exploit profitable opportunities in volatile environments, i.e. also a goal of structural flexibility; a foundation of horizontal supply chain management. Consequently, a horizontal supply chain implementing structural flexibility is fundamental in managing a network of partners and suppliers as emphasized by the Toyota way (Ko et al., 2011). Therefore, horizontal supply chain collaboration can be considered to represent a Lean enterprise where 'the companies joined ... must target the best opportunities for exploiting their collective competitive advantage' (Womack and Jones, 1994).

The study was performed from an SME perspective. This means that the customer's perspectives or legal issues of so called, "alliancing" was not considered and is therefore unknown in this work. However, it is certainly relevant to examine the true benefit of horizontal collaboration, considering increased sales and improved production efficiency as well as the potential impact of a negative impact to the individual SME brands that can be caused by "alliancing". In further work such a total cost analysis should be performed, similar to the total cost analysis performed of a supplier-builder purchasing relation in Bildsten et al., 2010.

\section{Conclusions}

An analysis of economic data from the development of the national Swedish timber industry during the economic crisis (2008-2010) indicates that the amount of bankruptcies of SME in the northern Swedish timber industry has been fewer than the average number of bankruptcies in the rest of the country. The reasons for this can be many but the authors firmly believe that horizontal supply chain collaboration among the SME is one reason, certainly among others, as horizontal supply chain collaboration provides a flexible business climate leading to improved SME competitiveness and survivability on a volatile market.

\section{Acknowledgements}

We extend our gratitude to project leaders Christer André, John Sandström and Sigurd Skotte for invaluable insights into activities in the Swedish and Norwegian networks.

\section{References}

Barratt, M. (2004). Understanding the Meaning of Collaboration in the Supply Chain, Supply Chain Management: An International Journal, 9(1), 30-42.
Bildsten, L., Björnfot, A. and Sandberg, E. (2011). ValueDriven Purchasing of Kitchen Cabinets in Industrialized Housing, Journal of Financial Management of Property and Construction, 16(1), 7383.

Björnfot, A. and Stehn, L. (2005). Product Design for Improved Material Flow - a Multi-Storey Timber Housing Project, Proceedings of the 13th Annual Conference on Lean Construction, Sydney, Australia.

Björnfot, A. and Stehn, L. (2007). Value Delivery through Product Offers: A Lean Leap in Multi-Storey Timber Housing Construction, Lean Construction Journal, 3(1), 33-45.

Cao, M., Vonderembse, M., Zhang, Q. and Ragu-Nathan, T. S. (2010). Supply Chain Collaboration: Conceptualisation and Instrument Development, International Journal of Production Research, 48(22), 6613-6635.

Carpinetti, L., Gerolamo, M. and Galdamez, E. (2007). Continuous Innovation and Performance Management of SME clusters, Creativity and Innovation Management, 16(4), 376-385.

Christopher, M. and Holweg, M. (2011). Supply Chain 2.0: Managing Supply Chains in the Era of Turbulence, International Journal of Physical Distribution \& Logistics Management, 41(1), 63-82.

Cressy, R. and Olofsson, C. (1997). European SME Financing: An Overview, Small Business Economics, 9, 87-96

Greenhalgh, R. (2000). Information and the Transnational SME Controller, Management Accounting and Research, 11(4), 413-426.

Ko, C. H., Wang, W. C. and Kuo, J. D. (2011). Improving Formwork Engineering using the Toyota Way, Journal of Engineering, Project, and production Management, 1(1), 13-27.

Lennartsson, M. and Björnfot, A. (2010). Step-by-Step Modularity - a Roadmap for Building Service Development, Lean Construction Journal, 2010, 717 729.

Lou, Y. (2007). Are Joint Venture Partners more Opportunistic in a more Volatile Environment?, Strategic Management Journal, 28, 39-60.

Lu, W., Olofsson, T. and Stehn, L. (2011). A Lean-Agile Model of Homebuilders' Production Systems, Construction Management and Economics, 29(1), 2535.

Mason, R., Lalwani, C. and Boughton, R. (2007). Combining Vertical and Horizontal Collaboration for Transport Optimization, Supply Chain Management: An International Journal, 12(3), 187-199.

Nilsson, A. (2010). Balancing the Management Control Package of Small, Rapidly Growing Firms in Turbulent Environments. International Journal of Entrepreneurship and Small Business, 11(1), 3-24.

Power, D. (2005). Supply Chain Management Integration and Implementation: A Literature Review, Supply Chain Management: An International Journal, 10(4), 252-263.

Prakash, A. and Deshmukh, S. G. (2010). Horizontal Collaboration in Flexible Supply Chains: A Simulation Study, Journal of Studies on Manufacturing, 1(1), 54-58.

Radas, S. and Božić, L. (2009). The Antecedents of SME Innovativeness in an Emerging Transition Economy, Technovation, 29(6-7), 438-450. 
Sacks, R.. (2004). Towards a Lean Understanding of Resource Allocation in a Multi-Project SubContracting Environment, Proceedings of the 14th Annual Conference on Lean Construction, Elsinore, Denmark.

Sandberg, E. (2007). Logistics Collaboration in Supply Chains: Practice vs. Theory, The International Journal of Logistics Management, 18(2), 274-293.

Simatupang, T. and Sridharan, R. (2002). The Collaborative Supply Chain, The International Journal of Logistics Management, 13(1), 15-30.

Höök, M. and Stehn, L. (2008). Lean Principles in Industrialized Housing Production: The Need for a Cultural Change, Lean Construction Journal, 2008, 20-33.

Womack, J. and Jones, D. (1994). From Lean Production to the lean Enterprise, Harvard Business Review, March-April 1994, 93-103.

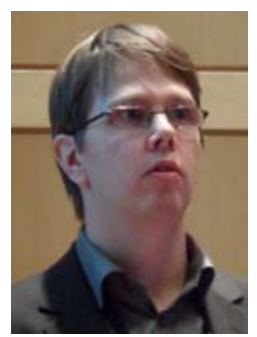

Dr. Anders Björnfot has an MSc in timber engineering from 2001 and took his $\mathrm{PhD}$ in Lean Construction of multi-storey timber structures in 2006. Anders is currently working as an Assistant Professor at the division of Structural and Construction Engineering at Luleå University of Technology, Luleå, Sweden. Anders also currently works as an Assistant Professor at the Faculty of Technology, Economy and Management, Gjøvik University College, Gjøvik, Norway. Anders has actively taken part in the International Group of Lean Construction (IGLC) since 2004 and consistently reviews research papers for both the annual IGLC conferences as well as the Lean Construction Journal. Anders research interests include, but are not limited to, everything Lean, Industrial house-building, Marketing, Operations management and Supply Chain Management (SCM).

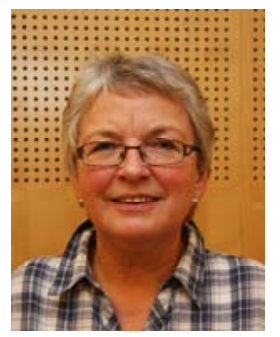

Mrs. Liv Torjussen is currently working as Assistant Professor at the Faculty of Technology, Economy and Management, Gjøvik University College, Gjøvik, Norway. Liv also holds the position of Vice-Dean for the faculty and is deeply involved in educating construction engineers. Liv is currently involved in the development of a Master of Science program in Sustainable manufacturing and Sustainable building production. Liv is also involved in Trehus Innlandet, a network of companies' active in the Norwegian timber construction value chain. Livs research interests include, but are not limited to, construction of glulam timber structures. 